\title{
Schema-Based Analysis of Gendered Self-Disclosure in Persian: Writing for Dating Context
}

\author{
Ebrahim Khodadady (Corresponding author) \\ Department of English Language and Literature, Ferdowsi University of Mashhad \\ Mashhad, 91779-48883, Iran \\ Tel: 98-91-5157-0733Ｅ-mail: ekhodadady@ferdowsi.um.ac.ir
}

Somayeh Javadi Mehr

Department of English Language and Literature, Ferdowsi University of Mashhad, Iran

E-mail: S_javadi223@yahoo.com

Received: August 28, 2011

Accepted: September 26, 2011

Published: January 1, 2012

doi:10.5539/elt.v5n1p20

URL: http://dx.doi.org/10.5539/elt.v5n1p20

\begin{abstract}
This paper reports a textual analysis of letters written by 21 male and 21 female participants in Persian. Each writer wrote two letters, one to a dating service and another one to a hypothetical person chosen and introduced by the center. Therefore, a total of 84 letters were collected from the participants. Schema theory was used to find the possible gendered differences between male and female self-disclosure letters. The results of this study confirmed that men and women used significantly different semantic, syntactic and parasyntactic schemata $\left(X^{2}=30.37, \mathrm{df}=2\right.$, $\mathrm{p}<.0001$ ), they also wrote differently in terms of the type of schemata forming the genera of the domains. Further descriptive analysis indicated that semantic domain accounted for $74.44 \%$ of all schema types used in male letters and $78.98 \%$ of the schemata used in female letters.
\end{abstract}

Keywords: Schema, Gender, Self-disclosure, Persian language

\section{Introduction}

Every one view the world through the lens of schemata he has internalized in various ways, these schemata are in part related to the gendered identity believed to be shaped in society through interaction. Gendered schemata illustrate themselves in one's writing and speaking. They explain why men and women resort to different strategies and discourse markers to gain recognition in an act of communication. Indeed, men and women obey rules of femininity and masculinity when they begin any human interaction. To do so, they need to recognize those discourse schemata which are illustrated through feminine/masculine vocabularies, grammatical devices and prosodic features to construct their favorable gendered identity. It builds on activation of individuals` related gendered schemata without which any female or male identity cannot be enacted. These dichotomous categories of gender enactment in communication are assessed via schemata theory by employing either a macro or micro structural approach. While the former defines schema as scripted or rhetorical knowledge, i.e., knowing the structural pattern of various texts such as narratives, and expository (McNeil, 1987; Poplin, 1988, Brown \& Yule, 1989), the latter views schema as a word used in an authentic and unmodified text whose juxtaposition and combination with the other words expresses whatever concepts the author of the text whishes to convey (Khodadady1997, 1999a, Khodadady \& Herriman, 2000).

In this study, schemata used by both men and women to do self-disclosure for finding their favorable partners were assessed via employing the micro structural view which addresses the schematic gendered identity more objectively by adopting contextual words/phrases as the smallest units carrying schematic meanings.

\subsection{Construction of Social Identity}

Language is not just for conveying content but about the presentation of self and identity. Social identity is enacted within social interaction (Coupland, 1996, Collier \& Thomas, 1988). Situational variations have a crucial effect on the type of discourse a person decides to follow (Hogg \& Rigoli, 1996). In other words, depending on their social goals, people vary their linguistic style and decide to emphasize or de-emphasize some aspects of their personality, 
this way; they diverge or converge with their interlocutors through interaction (Burgoon, Stern \& Dillman, 1955). For example, a person who wishes to be identified as an academic member needs to employ linguistic devices in a particular way to serve this purpose. He needs to use the sort of academic vocabularies which are typical of academic contexts, besides, he needs to know and use discourse markers which are assumed as characteristic tools of such a context. All this is done to construct one's academic identity through the vehicle of language to be distinguished as an academic member. Therefore, the assertion that social identities are enacted within social situations indicates that identities are not given to a person but emerge in the context through interaction.

According to Communication Adaptation Theory, which takes its value from the way it addresses the nature of identity construction, individuals attune their communication in interactions. It explains why male and female choose different styles to express themselves (Coupland, 1996). Another example of social contexts where men and women can enact their different sex-linked identity is when they need to establish intimacy with another person. Disclosure is an important social tool which happens in interactions and helps the development of intimacy. Through disclosure individuals reveal some aspects of their personality, feelings, ideas and beliefs which are hidden for others (Brunell, Pilkington, \& Webster, 2007).

Identity construction occurs through both spoken and written discourses; however, discourse markers which enact social identities are different in oral and written communication. While individuals use prosody, kinesics and other signals to express some aspects of their message in speaking, punctuation and some other transitional devices serve this purpose in writing (Tannen, 1982).

\subsection{Gender and Language}

One's gender- most typically as man or woman- is one of the most frequently mentioned identities when people are asked to describe themselves. Men and women are different in the way they think, feel and act, in fact, one of the most striking differences between the sexes is the unique way that men and women communicate. Language is a tool by which men and women construct their gendered identity and their language can be differentiated in various marked ways.

Women, for example, use "neutral language" for business context; however, they use more feminine language when they are in a friendly context. Women adapt their style occasionally to attune it to the whims of the moment. However, men from childhood have dominated society and speech by using "strong expression" (Lakoff, 1975).

Women have the tendency to use "Sex Prestige Pattern" more than males do (Hudson, 1996). In fact, they virtually in all societies tend to use more standard variants, defined as standard norms which are different from every day speech, in comparison with men. Robin and Greene (1992) carried out a study on language differences of men and women and concluded that exclamation points are typically reported to be used by females significantly more than by males.

Colley and Todd (2002), for example, asked college students to compose emails describing a recent holiday to an imaginary friend interested in going to the same location. They coded their written texts for the frequency of language features like indicators of excitibility, nonessential, hedging and tag questions. Like the previous researches, they found that women used more nonessentials and excitability markers than men. They also drew the conclusion that female participants employed more hedging and tag questions than their male counterparts.

Dating context is another social context where participants attempt to construct their gendered identity (Coupland, 1966). Dating advertisements sent for mating centers act as the first presentation of a person. Individuals need to describe themselves honestly and clearly to the mating center to match their data with their favorite partner. To do so, they have to highlight some aspects of their character which they consider significant to be expressed to find compatible mates (Coupland, 1966). Win and Rubin (2001) investigated ways in which gender is constructed in the written language of personal ads. The participants were asked to compose two separate written ads as a self description and their findings indicated that women were about 3 times more likely to produce markers of nonessential information like dashes and parentheses than men. Women also used more excitability markers and hedging and connective devices than men. In another study Brunell, Pilkington, and Webster (2007) examined dating couple's conversational reciprocity (participants' disclosure depth during conversation) to assess the moderating roles of gender differences in the strength of disclosure reciprocity in couple's conversations. They found that women's report of their own and their partner's disclosure had positive relationship with greater disclosure reciprocity.

\subsection{Schema}

\subsubsection{Definition of the Term}

A schema is a cognitive framework or concept that helps organize and interpret information. It was developed by 
Gestalt Psychologist Bartlett (1932) to account for how information in stories and events is reconfigured in memory for further recall; he used the term schema to refer to such past experiences. Schemata can be useful, because they allow us to take shortcuts in interpreting a vast amount of information. Since schemata are in every text, all acts of text analysis can indeed be performed to assess the schemata used in various types of texts. There are two approaches to employ schema theory for analyzing texts, namely macro and micro structural approaches. The macro structural approach defines schema as scripted or rhetorical knowledge. In this sense, knowing schema means knowing the structural patterns of various texts such as narratives and expository ones (Mc Neil, 1987; Poplin, 1988). However, the micro structural approach of schema theory approaches words/phrases constituting a given text as its smallest units which carry the intended meaning of its author. In the last three decades, many researchers have followed these approaches to capture the schemata used in different text types two good examples of which are discourse and meta discourse analyses.

\subsubsection{Discourse Analysis Approaches}

\subsubsection{Register Analysis}

Discourse analysis has undergone many levels of change, from the surface level of register analysis to the deeper level of genre analysis. Register analysis following micro structural approach of schema theory focuses on the identification of lexis and grammar points which are statistically significant in a given text (Hill, 1958, Barber, 1962, Crystal \& Davy, 1969). This approach of discourse analysis only takes into accounts the frequency of occurrence of some intended forms, therefore, it fails to differentiate different texts using the same number of register words but having different communicative purposes. This deficiency in considering communicative purpose of a text made researchers of the field to look for another method which could yield a better account of the functional units of texts. This attempt led them towards deeper levels of analysis, i.e., genre analysis.

\subsubsection{Move Analysis}

Genre analysis which entails an in-depth analysis of the communicative layers of a text tries to begin the task of analyzing a text or, to say in plain words, identification of the employed schemata from functional levels. To follow this macro structural view of schema theory, first, communicative units of a text type are extracted then the analyst goes through the text to explore the formal manifestations of the extracted communicative units. In order to achieve this purpose, the discourse analyst is provided with the definition of moves or functional units which act as the basic criteria to determine the boundaries of each communicative unit. To define moves, Swales (1990) focused on the communicative purpose of the text and considered the expectations of the audience or the speech community for which the text is written as an effective factor in shaping different moves. Later, Bhatia (1993) modified this definition by asserting, "Each move also serves a typical communication intention which is always sub-servient to the overall communicative purpose of the genre" (p.30).

Using these terms and under the name of generic move analysis, many scholars have attempted to investigate different texts to explore the type of schemata language users employ (Taylor \& Chen, 1991, Henry\& Roseberry, 2001, Smith, 1984, Hutchinson, 1987, Nwogu, 1997, Ruiying \& Allison, 2003). Swales (1981), for example, explored the introduction part of research articles and came up with a four-moves and 11 steps model which later was refined to a 3-moves and 11 steps model including the move categories of Establishing the field, Summarizing the relevant previous research, Preparing for present research and finally Introducing the present research. Pintos dos Santos (2002) analyzed move patterns of business letters of negotiation and provided a model of 4 moves of Establishing the negotiation chains, Providing information/answers, Requesting information/action/favors, and Ending. Brett (1994) followed the same tradition of genre analysis and analyzed the result section of research articles. He classified moves of the result section in three classes of Meta textual, Presentational and Comment categories. Research abstracts which are considered as an important academic genre have also been the subject of many move analysis studies (e.g., Bhatia, 1993, Martin, 2003, Swales, 1990). Bhatia (1993), for example, classified RAs as Introduction, methodology, Results and Conclusion moves.

\subsubsection{Meta discourse Analysis}

In conjunction with all these efforts to identify the underlying schemata of a text via discourse analysis methods, studies on the type of meta discoursal schemata which shapes the organization of a text became the subject of further analysis for the scholars of the field. Meta discourse has been another area of interest for text analysts which employ the macro structural approach of schema theory. Meta discourse, which is defined as devices by which a writer helps his readers organize, clarify, interpret, evaluate and react to the propositional content provided on the level of discourse, scrutinizes the strategies used to signal the presence of the author (Vande Koppel, 1985). Hyland (1999a) classifies all these purposes in two general categories of textual Meta discourse and interpersonal Meta discourse. 
He then stated their functions in details with some examples from the linguistic representations of these categories presented in the Table 1.

In all these genre and meta discourse studies, the basic unit of analysis was defined as communicative and functional rather than formal, therefore, the analyst had no objective criteria to determine the boundaries of employed schemata within a text. Apparently, these approaches bring about many ambiguities regarding making rigorous consensus on the boundaries of communicative units which, in turn, pushes analysts towards the subjective end of the assessment continuum.

\subsubsection{The New Concept of Schema}

Based on the revision of all that is done in the realm of text analysis, both discourse and meta discourse, it can be concluded that the macro structural definition of schema theory is unable to provide an objective tool to assess the employed schemata within a text, and micro structural approaches like register analysis cannot account for the texts using the same registers but serving different communicative purposes. The shortcomings of these approaches necessitate a new definition of schema which, on the one hand, provides an objective measure for the identification of schemata comprising a text and, on the other hand, could account for the functional levels of the text too. Khodadady (1997) and Khodadady and Herriman (2000) provided a new definition of micro structural approach of schema theory to explain the nature of alternatives employed in multiple choice items and used the term competitives to differentiate them from distracters, their traditional counterparts. While distracters are chosen on the basis of test writers' intuition, competitives bear semantic, syntactic and discoursal relationships with the keyed response and are thus superior to distracters in terms of their theoretical as well as pragmatic foundation.

The micro structural approach of schema theory classifies all the constituting words/phrases of texts into three domains, i.e., semantic, syntactic and parasyntactic. Semantic schemata are open in nature because new adjectives, adverbs, nouns and verbs are added when new actions, attitudes, feelings and states are used. They are many in type but few in frequency. The second domain is syntactic which is closed in nature and includes auxiliaries, conjunctions, determiners, prepositions and pronouns. Unlike semantic schemata, they are few in type but many in frequency. The third domain is parasyntactic class of schemata which comprise abbreviation, names, numerals and para adverbs. While parasyntactic schemata such as numerals may, for example, be many in type as semantic schemata are, they always perform a syntactic function.

Khodadady and Seif (2006) and Khodadady and Elahi (2012) defined a schema as a single word/phrase used along with other words/phrases to form an authentic text uttered or written under real circumstances in real places at real time for real purposes. Approaching schemata from a textual perspective provides researchers with an objective measure to study them empirically. It is argued that each and every schema used in an authentic and unmodified text expresses whatever concepts the author of the text wishes to convey if it is understood not only by itself but also in relation to other schemata forming the whole text (Khodadady 1997, 1999a, Khodadady \& Herriman, 2000).

According to the new definition of schema which is the underlying theory of the current study, words/phrases used together in spoken or written texts are treated as schemata which carry all pieces of information the authors of the texts intend to share with their addressees. They, therefore, differ from words which are considered as abstract linguistic units found in references such as dictionaries. Based on what was mentioned in the preceding discussion, there are three main merits inherent in the application of this new definition of schema theory for text analysis.

1. Unlike macro structural approach which does not provide any objective criterion for text assessment, based on the new definition, the job of analysis begins from the very words, i.e., schemata, by themselves and in juxtaposition with each other and thus eliminates the problem of having subjective criteria for analysis.

2. In the previous methods which followed micro structural approach of schema theory, form of the words were separated from their function, but in the recent definition of schema, words employed in letters have both formal and functional values and they are both considered when classifying them into their due categories. Therefore, unlike register analysis, the new approach can differentiate texts with different communicative purposes.

3. Schema includes both discourse and metadiscourse analysis. By carrying out schema-based analysis both discourse and metadiscourse features can be spotted.

This new approach to schema theory offers words/phrases used in texts as discourse and metadiscourse constituents and assigns them to their due codified categories, a demonstrative example of which is provided for the meta discourse categories of Hyland (1999a). Table 1 shows how examples of each single metadiscourse category can be codified by employing the semantic, syntactic and parasyntactic domains of schemata. The very adoption of schemata as the constituting units of discourse and their codification provides researchers with an objective measure 
to draw explanatory decisions missing in all types of macro structural approach to discourse analysis.

\subsection{Aims of the Study and Research Hypotheses}

The current study was conducted as a means of further investigation of gender linked use of Persian language. Schemata were employed as the units of analysis and points of departure to study and compare the written language produced by men and women. Below are the hypotheses formulated for this study.

H1. The semantic, syntactic and parasyntactic schemata used by female and male participants differ significantly from each other.

H2. The adverbs, adjectives, nouns and verbs forming semantic schemata used by male and female participants differ significantly from each other.

H3. The auxiliaries, determiners, preposition, pronouns and determiners forming syntactic schemata used by female and male participants differ significantly from each other.

H4. The abbreviations, names, numerals, para-adverbs forming parasyntactic schemata produced by female and male participants differ significantly from each other.

H5. The 13 genera of schemata forming semantic, syntactic and parasyntactic domain and produced by male and female participants differ significantly from each other.

H6. The syntactic, semantic and parasyntactic schemata of task1 and task 2 produced by female participants differ significantly from each other.

H7. The syntactic, semantic and parasyntactic schemata of task 1 and task 2 produced by male participants differ significantly from each other.

\section{Methodology}

\subsection{Participants}

A total of 42 undergraduate students participated in the study from which 21 participants were female and 21 participants were male. Female participants were chosen from the major of TEFL, but male participants were majoring in Chemical Engineering. They received course credit for their involvements in the study.

\subsection{Tasks}

Participants engaged in two writing tasks in Persian, which was their native language. For the first, they wrote self descriptions that would hypothetically be submitted to an online dating service. Participants were instructed to represent themselves as honestly as possible so that the dating service could match them with ones who would be truly compatible. The first writing task was intended to assess each participant's base line gender schemata in dating context. They were also instructed to underline those aspects of their personality which they found significant to be revealed to the dating service. This way, they could give the maximum chance to the hypothetical dating service to match them with their favorable partner. Moreover, participants were asked to write their self report letters so that they can attract their potential partner.

Following the first letter, the participants were asked to write another to provide further self-disclosure to their hypothetical partners whose e-mail addresses were provided by the match making center. In this letter, the writers were to reveal more detailed information about their personality, beliefs and feelings and whatever they thought were important and had to be known by their partner. To create the utmost level of privacy, the participants were assured that match making center would never know anything about the content of their letters. Both letters were individually typed and e-mailed by participants to an email address devised for this purpose by the researchers. Participants had the permission to send their emails anonymously if they wished so.

\subsection{Schema Codification}

The scheme used for coding features of gendered identity was based on the assumption that schemata are the smallest units of texts which carry meaning (Khodadady1997, 1999a, Khodadady \& Herriman, 2000). Letters produced by participants were classified to four categories of task 1-letters by males, task2-letters by males, task 1-letters by females and task2-letters by females. Using Microsoft Word parser all texts were broken into their constituting schemata and then were pasted on Excel sheets. Letters belonging to each category were one by one broken into their building schemata and sorted on Excel sheets. To do sorting, schemata elicited for each letter were coded in terms of their domain, genera, species, types and tokens. The semantic domain, for example, consists of four genera, i.e., adjectives, adverbs, nouns and verbs. The genus of adjective in turn comprises various species such as agentive, comparative, dative and superlative adjectives. A specific species such as agentive adjectives consists of 
many types such as ASHEGH (loving) and KHANEVADEH DOOST (family-loving). Female participants, for example, used the agentive adjective type ASHEGH 15 and 13 times in tasks one and two, respectively, as their token or frequency.

\subsection{Data Analysis}

In order to determine whether semantic, syntactic and parasyntactic domains, genera and types written by male and female participants differed significantly from each other or not, Chi-Square test was employed. According to Brown (1988) "the central question underlying this family of statistics is whether the observed frequencies for the different categories within the variables are related or independent" (p.184). The SPSS software, version 15, was used for all statistical analyses.

\section{Results}

Table 4 presents the descriptive statistics and Chi square test of three domains of semantic, syntactic and parasyntactic schemata comparing male and female participants. As can be seen in table 4, women and men differ significantly from each other in terms of these three domains $\left(X^{2}=30.37, \mathrm{df}=2, \mathrm{p}<.0001\right)$. In other words, the first hypothesis that male and female participants used significantly different semantic, syntactic and parasyntactic schemata is confirmed.

Table 5 addresses the second hypothesis of the study that female and male writers employed significantly different number of adjectives, adverbs, nouns and verbs. As shown in Table 5, while male participants used 820 adjectives, female writers employed far more adjectives, i.e., 1035. Similarly, the frequency or token of noun schema types for men was 2204, but 2799 for women. From the results provided in the table 5, we draw the conclusion that women and men differed significantly from each other regarding these four specified genera of schemata $\left(\mathrm{X}^{2}=23.18, \mathrm{df}=\right.$ $3, p<.0001)$.

Table 6 presents the descriptive statistics and Chi square test of genera forming the syntactic schema domain. As is evident, they are significantly different from each other $\left(\mathrm{X}^{2}=14.96, \mathrm{df}=4, p<.005\right)$. Therefore, the third hypothesis is confirmed that men and women used significantly different number of auxiliaries, conjunctions, determiners, prepositions, and pronouns in their letters.

Table 7 presents the descriptive statistics and Chi square test of genera forming the parasyntactic domain. As can be seen, they are significantly different from each other $\left(\mathrm{X}^{2}=23.74, \mathrm{df}=3, p<.0001\right)$. The results given in Table 7 confirm the fourth hypothesis that para-adverbs, interjections, names and numerals forming the parasyntactic domain are significantly different in type. Male participants, for example, used 109 determiners; however, women used only 63 determiners in their letters. Male participants wrote 283 pronouns of all type, whereas the number was only 249 for female participants. The frequency number of names was 122 for women and only 62 for male participants.

Table 8 presents the descriptive statistics and Chi- square test of all genera forming the three main domain types forming the letters by male and female writers. As can be seen, they are significantly different from each other $\left(\mathrm{X}^{2}=\right.$ $90.93, \mathrm{df}=12, p<.0001)$. These results confirm the fifth hypothesis that the 13 genera form the semantic, syntactic and parasyntactic schemata of dating letters written by male and female participants were significantly different.

As shown in Table 9, female writers used different types of semantic, syntactic and parasyntactic schemata for the first and the second tasks. (For the first task, they wrote to the dating center with no specified audience, however, in the second task, they were supposed to write a personal letter to a partner introduced by the center). The Chi square test showed that the difference in schema types is significant $\left(X^{2}=17.12, \mathrm{df}=2, \mathrm{p}<.001\right)$ and thus confirmed the sixth hypothesis.

As presented in Table 10, male participants of the study used significantly different number of semantic, syntactic and parasyntactic schemata in their tasks 1 and $2\left(\mathrm{X}^{2}=7.68, \mathrm{df}=2, \mathrm{p}<.02\right)$ Therefore, the last hypothesis is also confirmed.

Table 11 provides the percentage of semantic, syntactic and parasyntactic genera used in the letters written for task 1 and 2 by both male and female participants. As is evident in the table, semantic domain of schema makes up $74.44 \%$ of letters produced by male and $78.98 \%$ of the total letters written by female participants. It is also noticeable that nouns had the highest level of use among both male and female participants in dating context $(41.90 \%$ of male letters and $46.61 \%$ of female participants' letters).

\section{Discussion}

The contrastive analysis of language used by male and female writers in the two letters composed for the present study revealed the fact that participants' gender affected their language in terms of the type of schemata they 
produced to highlight some aspects of their personality in two specific and distinct dating contexts, i.e., publically and privately. It was found that men and women employed significantly different number of semantic, syntactic and parasyntactic schemata to describe themselves publically in general and privately in particular.

More specific analysis of schemata extracted from the letters, however, showed that male and female participants had some similarities in their use of schemata in dating contexts. First, they both employed semantic schemata more frequently than syntactic and parasyntactic domains. Secondly, compared to other genera of semantic domain, both men and women had the tendency to use more nouns to describe themselves favorably. And finally, both genders used almost the same percentage of adverbs to disclose some aspects of their character in the two tasks. The results also revealed that syntactic and parasyntactic schemata made up a minor part of their letters written for public and private purposes.

The study, nonetheless, documents some distinct differences. It provides evidence for the fact that women are likely to use more adjectives than men to describe themselves. The same tendency is also seen in the women's use of noun genus in both public and private contexts. The analysis of syntactic genera indicated that women were less likely to use more pronouns than male writes of the study, which can partly be justified by the idea that men are not only more willing but also more self-confident to refer to themselves in their letters. A comparative analysis of semantic and parasyntactic domains, however, revealed that women were likely to use more names in their letters than men. It provides evidence to the fact that women are more specific in their descriptions as reflected in their more frequent application of adjectives and names. In contrast, the more frequent use of numerals among male writers indicates that men provide their detailed descriptions by resorting to parasyntactic domain only.

The application of specific domains by females and males seems to be context-bound. The analysis of females' letters written for task 1 and 2, for example, showed that women used more syntactic schemata when they wrote their letters to a hypothetically chosen and introduced partner (Table 9). The more frequent use of syntactic schemata by female writers indicated that women paid more attention to their style when writing to a particular person than having no specific audience in mind. These results support Khodadady and Elahi's (2012) argument that schemata are personal and thus depend on the conditions, locations, time they are produced and the kind of impression they intend to produced in their addressers. The same tendency was also evident in men's letters (see Table 10). They used syntactic devices more frequently when they introduced themselves to their potential partners suggested by the service. These findings show that both men and women tend to be more stylistic and formal when they know their letters will be read by their intended addressees and thus may be used to argue that the application of syntactic domain is not gender controlled.

\section{Conclusion}

Schema theory provides researchers with an objective measure to analyze texts for different purposes. The results of the present study, for example, confirm that the schema-based analysis of texts can reveal the differences between the language of men and women in specific dating context. The theory encompasses all concepts expressed by language users which are subsumed under three domains, i.e., semantic, syntactic and parasyntactic. On one hand these results provide empirical evidence to establish the psychological validity of the domains themselves and, on the other hand, the domains are suggested to be used to study the differences between male and female languages in various contexts. They also specify the type of schemata required to be learned and modified if proficiency is sought in the language under study. In other words, the schema theory shows, in objective terms, what type of schema domains and genera must be learned and mastered by learners in order to be recognized as competent language user in specific social contexts.

Since the findings of this study show that writers in the Persian language use semantic domain of schema more frequently than syntactic and parasyntactic ones, textbook writers need to invest more time and attention on this domain in general, and on its noun genus in particular. Similarly, the instructors of English as a foreign language need to spend more time on semantic schemata by employing the appropriate percentage of schema domains and genera whose empirical validity is established in various studies such as the present one. Future research must show whether similar patterns of significance will be found if the schema-based analysis is extended to authentic dating letters written in both English and Persian.

\section{References}

Barber, C. L. (1962). Some measurable characteristics of modern scientific prose in contribution to English syntax and phonology. Stockholm: Almquist \& Wiksell. pp. 1-23

Bartlett, F. C. (1932). Remembering. Cambridge: CUP.

Bhatia, V. K. (1993). Analyzing genre: Language use in professional settings. London: Longman. 
Brett, P. (1994). A genre analysis of the result section of sociology articles. English for Specific Purposes, 13(1), 47-59. http://dx.doi.org/10.1016/0889-4906(94)90024-8

Brown, G., \& Yule, G. (1989). Discourse analysis. New York: CUP.

Brunell, A. B., Pilkington, C. J., \& Webster, G. D. (2007). Perception of risk in intimacy in dating couples: Conversation and relationship quality. Journal of Social and Clinical Psychology, 26, 93-117. http://dx.doi.org/10.1521/jscp.2007.26.1.92

Burgoon, J. K., Stern, L. A., \& Dillman, L. (1995). Interpersonal adaptation: Dyadic interaction patterns. New York: CUP. http://dx.doi.org/10.1017/CBO9780511720314

Colley, A., Todd, Z. (2002). Gender- linked differences in the style and content of e-mails to friends. Journal of Language and Social Psychology, 21(4), 380-392

Collier, M. J., \& Thomas, M. (1988). Cultural identity: An interpretive perspective. In Y.Y. Kim \& W. B. Gudykunst (Eds.), Theories in intercultural communication. Newbury Park, CA: Sage. pp. 99-122

Coupland, J. (1996). Dating advertisements: Discourse of the commodified self. Discourse and Society, 7, 187-207

Crystal, D., \& Davy, D. (1969). Investigating English style. London: Longman.

Henry, A., \& Roseberry, R. L. (2001). A narrow- angled corpus approach to the teaching of strategies of genre: Letter of application. English for Specific Purposes, 20, 153-167

Hill, A. A. (1958). Introduction to linguistic structure. NY: Harcourt, Brace \& Co.

Hogg, M. A., \& Rigoli, N. (1996). Effects of ethnolinguistic validity, ethnic identification, and linguistic contacts on minority language use. Journal of Language and Social Psychology, 15, 76-89

Hudson, R. A. (1996). Sociolinguistics. Cambridge: CUP.

Hutchinson, T., \& Waters, A. (1987). English for Specific Purposes, a learning centered approach. Cambridge: CUP. http://dx.doi.org/10.1017/CBO9780511733031

Hyland, K. (1999a). Talking to students: Meta- discourse in introductory course books. English for Specific Purposes, 18(1), 3-26. http://dx.doi.org/10.1016/S0889-4906(97)00025-2

Khodadady, E. (1997). Schemata theory and multiple choice item tests measuring reading comprehension. Unpublished PhD thesis. The University of Western Australia.

Khodadady, E. (1999a). Multiple choice items in testing: Practice and theory. Tehran: Rahnama.

Khodadady, E. (2008). Schema- based textual analysis of domain controlled authentic texts. Iranian Journal of Language Studies, 2(4), 431-446

Khodadady, E., \& Elahi, M. (2012). The Effect of schema-vs-translation-based instruction on Persian medical students' learning of general English. English Language Teaching, 5(1)

Khodadady, E., \& Herriman, M. (2000). Schemata Theory and Selected Response Item Tests: From Theory to Practice. In A. J. Kunnan (Ed.), Fairness and validation on language assessment. Cambridge: CUP. pp. 201-222

Khodadady, E., \& Seif. S. (2006). Measuring Translation Ability and Achievement: A schema- Based Approach. Paper presented at the third Annual Conference of the TELLSI, Razi University of Kermanshah, Iran.

Lakoff, R. (1975). Language and women's place. New York: Harper \& Row.

Martin, P. M. (2003). A genre analysis of English and Spanish research abstracts in experimental and social sciences. English for Specific Purposes, 22, 25-43

McNeil, J. (1987). Reading comprehension: New direction for classroom practice. Blenview, IL: Scott, IL, Foresman, and Company.

Nwogu, K. N. (1997). The medical research paper: Structure and functions. English for Specific Purposes, 1(2), 119-138. http://dx.doi.org/10.1016/S0889-4906(97)85388-4

Pintos dos Santos, V. B. M. (2002). Genre analysis of business letters of negotiation, English for Specific Purposes, 21(2), 167-199. http://dx.doi.org/10.2307/357609

Poplin, M. S. (1988). Holistic/ constructivist principles of the teaching/ learning process: Implications for the field of learning disabilities. Journal of Learning Disabilities, 21,401-416

Robin, D. L., \& Greene, K. (1992). Gender-typical style in written language. Research in the Teaching of English, 26, 7-40 
Ruiying, Y., \& Allison, D. (2003). Research articles in applied linguistics: Moving from result to conclusions. English for Specific Purposes, 22, 365-385

Smith, A. (1984). Medical discourse: aspects of author's comments. The ESP Journal, 3, 25-36

Swales, J. M. (1981). Aspects of article introductions. Birmingham, UK: The University of Aston, Language studies unit.

Swales, J. M. (1990). Genre Analysis: English in academic and research settings. Cambridge: CUP.

Tannen, D. (1982). The oral/ literate continuum in discourse. In D. Tannen (Ed.), Spoken and written language: Exploring orality and literacy. Norwood, NJ: Ablex. pp. 1-16

Taylor, G., \& Chen, T. (1991a). Linguistic cultural and sub - cultural issues in contrastive discourse analysis. Applied Linguistics, 3, 319-336. http://dx.doi.org/10.1093/applin/12.3.319

Van de Kopple, W. J. (1985). Some exploratory discourse on meta- discourse. College Composition and Communication, 36, 82-93

Winn, L. L., \& Rubin, D. L. (2001). Enacting gender identity in written discourse: Responding to gender role bidding in personal ads. Journal of Language and Social Psychology, 20(4), 393-418. http://dx.doi.org/10.1177/0261927X01020004001

Table 1. Textual metadiscourse and interpersonal discourse taken from Hyland (1999a)

\begin{tabular}{|c|c|c|}
\hline $\begin{array}{l}\text { Textual meta } \\
\text { discourse }\end{array}$ & Function & Example/signals \\
\hline Logical connectives & $\begin{array}{ll}\text { Express semantic } & \text { relation } \\
\text { between main clauses } & \end{array}$ & In addition/ but/therefore/thus \\
\hline Frame markers & $\begin{array}{l}\text { Explicitly refer to discourse shift } \\
\text { or text stages }\end{array}$ & First/finally/to repeat/ to clarify \\
\hline Endophoric markers & $\begin{array}{l}\text { Refer to information in other } \\
\text { parts of the text. }\end{array}$ & Noted above/see fig.1/section \\
\hline Evidential & $\begin{array}{l}\text { Refer to source of information } \\
\text { from other texts }\end{array}$ & According to X/1990/ Z states \\
\hline Code glosses & $\begin{array}{l}\text { Help readers grasp meanings of } \\
\text { ideational material }\end{array}$ & Namely/ e.g./ in other words/ i.e./ say \\
\hline \multicolumn{3}{|l|}{$\begin{array}{l}\text { Interpersonal meta } \\
\text { discourse }\end{array}$} \\
\hline Hedges & $\begin{array}{l}\text { Withhold writer's } \\
\text { commitment to statements }\end{array}$ & Might/perhaps/it is possible \\
\hline Emphatics & $\begin{array}{l}\text { Emphasis force or writer's } \\
\text { certainty in message }\end{array}$ & In fact/ definitely/ it is clear \\
\hline Attitude markers & $\begin{array}{l}\text { Express writer's attitude to } \\
\text { propositional content }\end{array}$ & Surprisingly/ I agree/ X claims \\
\hline Relational markers & $\begin{array}{l}\text { Explicitly refer to or build } \\
\text { relationship with reader }\end{array}$ & Consider/recall/imagine/you \\
\hline Person markers & Explicit reference to author(s) & $\mathrm{I} / \mathrm{we} / \mathrm{my} / \mathrm{mine} /$ our \\
\hline
\end{tabular}

Table 2. Schema domains and genera

\begin{tabular}{|l|l|l|l|l|l|}
\hline Domains & \multicolumn{5}{|c|}{ Genera } \\
\hline Semantic & Adjectives & Adverbs & Nouns & Verbs & \\
\hline Syntactic & Auxiliaries & Conjunctions & Determiners & Prepositions & Pronouns \\
\hline Para syntactic & Abbreviations & Names & Numerals & Para- adverbs & \\
\hline
\end{tabular}


Table 3. Schematic codification of Hyland's examples of the metadiscourse categories and examples

\begin{tabular}{|c|}
\hline Textual meta discourse \\
\hline Logical connectives \\
\hline But/ therefore :Syntactic schema (simple conjunction), codified as 2120 \\
\hline In addition: Parasyntactic schema ( additive para-adverb), codified as 3511 \\
\hline Thus: Para syntactic schema ( referential para- adverb), codified as: 3520 \\
\hline Endophoric markers \\
\hline Noted above: noted (semantic schema, past participle, simple verb), codified as 1443 \\
\hline above(parasyntactic schema, referential para-adverb), codified as 3520 \\
\hline See section: see (semantic schema, simple present verb), codified as 1447 \\
\hline Section (semantic schema, simple noun), codified as 1380 \\
\hline $\begin{array}{l}\text { Figure1: Figure (semantic schema, simple noun), codified as 1380, } 1 \text { (par syntactic schema, } \\
\text { numeral, digital), codified as } 3420\end{array}$ \\
\hline Evidential \\
\hline According to: syntactic schema (phrasal conjunction), codified as 2110 \\
\hline 1990: parasyntactic schema( numeral, date), codified as 3440 \\
\hline Code glosses \\
\hline Namely/ in other words: Parasyntactic schemata (exemplifying para- adverbs), codified as 3522 \\
\hline Interpersonal meta discourse \\
\hline Hedges \\
\hline Might: syntactic schema (past modal), codified as 2580 \\
\hline Perhaps: parasyntactic schema (contrasting para-adverb), codified as 3512 \\
\hline Emphatics \\
\hline In fact/ definitely: para-syntactic schemata (emphatic para-adverbs), codified as 3513 \\
\hline Attitude markers \\
\hline Surprisingly: semantic schema (derivational adverb), codified as 1220 \\
\hline Relational markers \\
\hline Consider/ recall/ imagine: semantic schemata (simple verbs), codified as 1447 \\
\hline Person markers \\
\hline $\begin{array}{l}\text { I/ we/ my / your: syntactic schemata (subject/ object/ possessive pronouns), codified as } 2470,2440 \text {, } \\
\text { 2441, respectively }\end{array}$ \\
\hline
\end{tabular}

Table 4. Descriptive statistics and chi square test of semantic, syntactic and parasyntactic domain types written by both sexes

\begin{tabular}{|l|l|l|l|l|l|}
\hline Hypothesis 1 & Semantic & Syntactic & Parasyntactic & Total & Test \\
\hline Male & 3947 & 873 & 440 & 5260 & $\begin{array}{l}\mathrm{X}^{2}=30.37 \\
\mathrm{df}=2 \\
p<.0001\end{array}$ \\
\hline Female & 4745 & 800 & 460 & 6005 & \\
& & & & & \\
\hline
\end{tabular}


Table 5. Descriptive statistics and chi square test of semantic genera types written by both sexes

\begin{tabular}{|c|c|c|c|c|c|c|}
\hline Hypothesis 2 & Adjectives & Adverbs & Nouns & Verbs & Total & Test \\
\hline Male & 820 & 67 & 2204 & 856 & 3947 & \multirow{2}{*}{$\begin{array}{l}\mathrm{X}^{2}=23.18 \\
\mathrm{df}=3 \\
p<.0001\end{array}$} \\
\hline Female & 1035 & 63 & 2799 & 847 & 4747 & \\
\hline
\end{tabular}

Table 6. Descriptive statistics and chi square test of syntactic genera types written by both sexes

\begin{tabular}{|l|l|l|l|l|l|l|l|}
\hline Hypothesis 3 & Auxiliaries & Conjunctions & Determiners & prepositions & Pronouns & Total & Test \\
\hline Male & 30 & 145 & 109 & 306 & 283 & 873 & $\begin{array}{l}\mathrm{X}^{2}=14.96 \\
\text { Female }\end{array}$ \\
& 46 & 138 & 63 & 304 & 249 & 800 & $\begin{array}{l}\mathrm{df}=4 \\
p<.005\end{array}$ \\
\hline
\end{tabular}

Table 7. Descriptive statistics and chi square test of parasyntactic genera types written by both sexes

\begin{tabular}{|l|l|l|l|l|l|l|}
\hline Hypothesis 4 & Interjections & Names & Numeral & Para adverbs & Total & Test \\
\hline Male & 75 & 62 & 303 & 1 & 440 & $\begin{array}{l}\mathrm{X}^{2}=23.74 \\
\mathrm{df}=3 \\
p<.0001\end{array}$ \\
\hline Female & 57 & 122 & 281 & 0 & 460 & \\
\end{tabular}

Table 8. Descriptive statistics and chi square test of all schema genera written by both sexes

\begin{tabular}{|c|c|c|c|c|}
\hline Genera & $\begin{array}{l}\text { Female (Observed } \\
\text { frequency) }\end{array}$ & $\begin{array}{l}\text { Male (Observed } \\
\text { frequency) }\end{array}$ & Total & Test \\
\hline Adjectives & 1035 & 820 & 1855 & \multirow{13}{*}{$\begin{array}{l}\mathrm{X}^{2}=90.93 \\
\mathrm{df}=12 \\
p<.0001\end{array}$} \\
\hline Adverbs & 63 & 67 & 130 & \\
\hline Nouns & 2799 & 2204 & 5003 & \\
\hline Verbs & 847 & 856 & 1703 & \\
\hline Auxiliaries & 46 & 30 & 76 & \\
\hline Conjunctions & 138 & 145 & 283 & \\
\hline Determiners & 63 & 109 & 172 & \\
\hline Prepositions & 304 & 306 & 610 & \\
\hline Pronouns & 249 & 283 & 532 & \\
\hline Interjections & 57 & 75 & 132 & \\
\hline Names & 122 & 62 & 184 & \\
\hline Numerals & 281 & 303 & 584 & \\
\hline Para adverbs & 0 & 1 & 1 & \\
\hline
\end{tabular}


Table 9. Descriptive statistics and chi square test of schema domain types produced by female writers in tasks 1 and 2 letters

\begin{tabular}{|c|c|c|c|c|c|}
\hline Hypothesis 6 & Semantic & Syntactic & Parasyntactic & Total & Test \\
\hline Task 1 & 2354 & 349 & 249 & 2967 & \multirow{2}{*}{$\begin{array}{l}\mathrm{X}^{2}=17.12 \\
\mathrm{df}=2 \\
p<.001\end{array}$} \\
\hline Task 2 & 2366 & 460 & 217 & 3048 & \\
\hline
\end{tabular}

Table 10. Descriptive statistics and chi square test of schema domain types produced by male writers in tasks 1 and 2 letters

\begin{tabular}{|c|c|c|c|c|c|}
\hline Hypothesis 7 & Semantic & Syntactic & Parasyntactic & Total & Test \\
\hline Task 1 & 1958 & 394 & 230 & 2582 & \multirow{2}{*}{$\begin{array}{l}\mathrm{X}^{2}=7.68 \\
\mathrm{df}=2 \\
P<.02\end{array}$} \\
\hline Task 2 & 1989 & 479 & 210 & 2678 & \\
\hline
\end{tabular}

Table 11. The percentage of semantic, syntactic and parasyntactic genera written by both men and women

\begin{tabular}{|l|l|l|l|}
\hline Domain & Genera & Female & Male \\
\hline \multirow{5}{*}{ Semantic } & Adjectives & $17.23 \%$ & $15 \%$ \\
\cline { 2 - 4 } & Adverbs & $1.04 \%$ & $1.27 \%$ \\
\cline { 2 - 4 } & Nouns & $46.61 \%$ & $41.90 \%$ \\
\cline { 2 - 4 } & Verbs & $14.10 \%$ & $16.27 \%$ \\
\hline \multirow{5}{*}{ Syntactic } & Auxiliaries & $0.76 \%$ & $0.57 \%$ \\
\cline { 2 - 4 } & Conjunctions & $2.29 \%$ & $2.75 \%$ \\
\cline { 2 - 4 } & Determiners & $1.04 \%$ & $2.07 \%$ \\
\cline { 2 - 4 } & Prepositions & $5.06 \%$ & $5.81 \%$ \\
\cline { 2 - 4 } & Pronouns & $4.14 \%$ & $5.38 \%$ \\
\hline \multirow{5}{*}{ Para syntactic } & Interjections & $0.94 \%$ & $1.42 \%$ \\
\cline { 2 - 4 } & Names & $2.03 \%$ & $1.17 \%$ \\
\cline { 2 - 4 } & Numerals & $4.67 \%$ & $5.76 \%$ \\
\cline { 2 - 4 } & Para adverbs & $000 \%$ & $.001 \%$ \\
\hline
\end{tabular}

